\title{
LA DEMOCRATIZACIÓN SUBNACIONAL DESDE LA PERSPECTIVA DEL ESTADO Y SU PODER DE POLICÍA. El CASO DEL JUARISMO EN SANTIAGo DEL Estero, Argentina, 1995-2004*
}

\author{
Sub-national democratization through the perspective of the \\ State and its police power. Juarismo's case in Santiago del Estero, \\ Argentina, 1995-2004
}

\author{
MARÍA CELESTE SCHNYDER \\ Universidad Nacional de Santiago del Estero, Argentina
}

\begin{abstract}
RESUMEN
El artículo analiza la democratización subnacional por medio del Estado y su poder de policía. Sostenemos que en las policías de algunos estados provinciales argentinos permanecen burocracias creadas en el periodo autoritario para el control político de los ciudadanos, por ejemplo el departamento de informaciones policiales (DIP), cuyos usos políticos pueden obstaculizar la institucionalización de la democracia. A base de un estudio de caso, el juarismo en Santiago del Estero, describimos el poder policial de su Estado plasmado en las funciones y atribuciones de la policía y su órgano de inteligencia e identificamos sus principales usos durante sus gobiernos entre 1995 y 2004.
\end{abstract}

Palabras clave: Democratización, Estado, poder de policía, control político, juarismo.

\begin{abstract}
The article analyzes sub-national democratization from the perspective of the state and its police power. We argue that in the police forces of some Argentine provinces the uses of bureaucracies created during the dictatorship to control citizens, the police information department (PID) for example, can become an obstacle for the institutionalization of democracy. Based on a case study, the "juarismo" in Santiago del Estero, we describe the provincial state police power revealed in the functions and prerrogatives of police and its intelligence agency, and examine its uses between 1995 and 2004.
\end{abstract}

Key words: Democratization, State, Police Power, Political Control, Juarismo.

* El presente artículo está basado en mi tesis doctoral “Política y violencia en la democracia argentina. La democratización subnacional a la luz de las prácticas partidarias y los usos de la policía durante el juarismo en Santiago del Estero" realizada con el financiamiento de las becas de postgrado Tipo I y II del Conicet. Agradezco las sugerencias y comentarios críticos de los evaluadores externos de la Revista de Ciencia Política que permitieron enriquecer este trabajo. 


\section{INTRODUCCIÓN}

Culminado el proceso de transición democrática y con la estabilización de sus instituciones en la región, emergió como un problema dentro de la agenda académica la democratización en los niveles subnacionales. La presencia a nivel provincial de gobernabilidades reñidas con los componentes liberales que resignificaron a nuestras democracias fue, en general, tematizada por el funcionamiento de sus regímenes políticos, relegando del análisis el accionar de un actor central para la democracia: el Estado. Su papel en la democratización de un sistema político no se reduce a su capacidad para extender los derechos económicos, civiles y políticos entre sus ciudadanos, a la eficacia de sus burocracias y/o la efectividad de su sistema legal, o al ejercicio desconcentrado de su poder. Existe una dimensión central para la construcción de una relación democrática del Estado con sus ciudadanos: su poder de policía. Esto es, un conjunto de prerrogativas que limitan derechos políticos y civiles con el objeto de preservar el orden público que se materializan en las leyes orgánicas de sus policías.

A partir del caso de Santiago del Estero -provincia del norte argentino donde el justicialismo fue el partido gobernante desde el retorno a la democracia y el juarismo su corriente interna dominante-, el artículo caracteriza el poder policial de su estado por medio del análisis del órgano de inteligencia policial e indaga sus usos políticos entre 1995-2004. El sector liderado por el caudillo Carlos Juárez fue gobierno en 1949, 1973, 1983, 1995, 1999, 2002 hasta que, en el 2004, el presidente Néstor Kirchner ordenó la Intervención Federal como consecuencia de la crisis institucional desatada por la protesta social y las repercusiones de la investigación judicial de los asesinatos de dos jóvenes mujeres que puso de relieve las complicidades político-policiales movilizadas para su encubrimiento. Por el "caso Dársena" fueron procesados funcionarios, policías $\mathrm{y}$ uno de los secretarios de inteligencia. El caudillo fue procesado por espionaje ilegal y delitos de lesa humanidad cometidos durante su mandato entre 1973 y 1976 que salieron a la luz durante las marchas de protesta organizadas por los familiares de las víctimas y distintas organizaciones sociales entre las que se destacaron las de derechos humanos y organismos pastorales del obispado.

La investigación adoptó una estrategia metodológica cualitativa y tuvo como técnica de recolección principal la entrevista en profundidad con dirigentes "de primera línea" del PJ juarista, funcionarios policiales y agentes que desempeñan funciones en el DIP. Debido a que los entrevistados solicitaron que sus nombres fueran mantenidos en el anonimato, en las citas usaremos nombres ficticios y solo serán identificados por su posición dentro del partido o la fuerza. Los testimonios obtenidos fueron contrastados con documentos policiales, informes relativos a la situación de los derechos políticos y civiles en la provincia, entrevistas con informantes calificados de organismos de derechos humanos, fotografías de algunos informes del archivo de inteligencia policial e informes periodísticos.

El artículo comienza con una revisión de los aportes de la perspectiva de los regímenes híbridos para abordar la complejidad de las construcciones políticas subnacionales, donde los procedimientos democráticos coexisten con gobernabilidades sostenidas en 
algunas prácticas autoritarias. Continúa con el análisis de los distintos aspectos en que un Estado puede fortalecer a la democracia para luego centrarse a nivel de su poder de policía, el reparto de jurisdicción entre el Estado nacional y provincias, y el vínculo entre los ejecutivos provinciales y sus policías. Luego describe las competencias específicas de la policía santiagueña y los usos políticos del Departamento de Informaciones Policiales (DIP) durante el juarismo.

\section{APORTES DE LA PERSPECTIVA DE LOS REGÍMENES HÍBRIDOS AL ANÁLISIS DE LA DEMOCRATIZACIÓN SUBNACIONAL}

Tras la tercera ola de democratización, a fines del siglo XX se produjo una redistribución de poder entre los gobiernos nacionales y locales que fue reforzada por las reformas de libre mercado que acompañaron a la expansión global de las democracias liberales (Snyder, 1999; Diamond, 2002). La permanencia de elites autoritarias a nivel subnacional y la formación de sistemas políticos centralizados y personalistas autonomizados de la política nacional dejó en evidencia la naturaleza territorialmente desigual de los procesos de democratización (Snyder, 1999 y 2001; Gibson, 2006). Los casos provinciales que no se ajustaban a los parámetros liberales comenzaron a ser pensados en nuevos términos. Ya no serían formas inconclusas de democracia o enclaves autoritarios como sostenía el paradigma transicional, sino un nuevo tipo de régimen político. Los regímenes híbridos, mixtos o ambiguos, designan a una combinación de rasgos autoritarios y reglas de juego democráticas (Levitsky y Way, 2002; Diamond, 2002; Schedler, 2002) que configurarían una "zona gris" de la política (Diamond, 2002; Schedler, 2002). Así emergió como un tema de la agenda de investigación de la política comparada el estudio del llamado autoritarismo competitivo (Levitsky y Way, 2002) o autoritarismo electoral (Schedler, 2002).

En el autoritarismo competitivo, un tipo específico de régimen híbrido ${ }^{1}$, las instituciones democráticas formales siguen siendo el principal medio para obtener y ejercer la autoridad política, pero las violaciones de los criterios mínimos de la democracia crearían un campo de juego desigual entre gobierno y oposición. No obstante, los líderes autoritarios competitivos "no pueden eliminar o reducir a una mera fachada" a las normas democráticas, las que los legitiman frente a otros actores institucionales (Levitsky y Way, 2004: 163).

“En lugar de infringir abiertamente los criterios democráticos -por ejemplo prohibiendo o reprimiendo a la oposición y a los medios informativos-, es más probable que empleen el soborno, la cooptación y formas más sutiles de acoso, como el uso de las autoridades tributarias, un poder judicial condescendiente y otros organismos del Estado para,

1 Otros tipos de regímenes serían las "repúblicas exclusivas -que poseen instituciones democráticas sólidas, pero leyes civiles muy restrictivas- y las democracias "tutelares" o "guiadas", es decir, regímenes competitivos en que actores no democráticos como el Ejército o las autoridades religiosas ejercen el poder de veto" (Levitsky y Way, 2004: 164). 
de manera 'legal', hostigar, perseguir y extorsionar a los críticos a fin de obtener una conducta cooperativa de su parte" (Levitsky y Way, 2011: 8).

El autoritarismo electoral, en cambio, es un sistema en el que "se llevan a cabo elecciones multipartidarias con regularidad en todos los niveles de gobierno, sin embargo violan gravemente y en forma sistemática las normas democráticas fundamentales" (Schedler, 2011: 135). Estos apelarían, en lugar del terror y la represión abierta como los totalitarismos y las dictaduras militares, a diversas formas de manipulación para mantener el control sobre sus representantes y sus adversarios en ámbitos institucionales como el poder legislativo y el poder judicial, los medios de comunicación, la sociedad civil. Estas manipulaciones y controles sentarían las condiciones por las cuales los partidos de oposición no tendrían posibilidades reales de ganar elecciones. En consecuencia habría competencia partidaria formal, pero no oportunidades efectivas de alternancia. Los líderes autoritarios tratarían de "cosechar los frutos de la legitimidad electoral sin correr los riesgos de la incertidumbre democrática" (Schedler, 2004).

En el marco del giro hacia los estudios subnacionales surgió en la región un nuevo objeto de estudio: el autoritarismo subnacional. Desde esta perspectiva el patrimonialismo, el nepotismo o las prácticas clientelistas -aspectos que fueron ampliamente trabajados por la sociología política- no eran suficientes para dar cuenta de un tipo de régimen que combinaba procedimientos democráticos con gobernabilidades autoritarias. El crecimiento de esta área de estudios -que se vio reflejado en la proliferación de investigaciones (Gibson, 2006; Gervasoni, 2005; Benton, 2007; Souza, 2009; Durazo Herrmann, 2010; Behrend, 2011), eventos científicos especializados ${ }^{2}$ y publicaciones específicas ${ }^{3}$ - representa una innovación frente a la tendencia de la teoría democrática a centrarse en la nación como una unidad política homogénea y percibir los casos provinciales como fenómenos marginales, sin incidencia sobre los procesos políticos nacionales. Estos estudios pusieron de manifiesto la experiencia desigual que tienen los ciudadanos de la vida democrática por su inscripción territorial.

El enfoque de los regímenes híbridos, desde nuestro punto de vista, ofrece ventajas para abordar las especificidades de la configuración del poder en los ámbitos provinciales y locales. Por un lado tiene la virtud de recuperar la dimensión territorial de la democratización, relegada por la focalización de la teoría democrática contemporánea en las instituciones, actores y movimientos nacionales (Gibson, 2006). Por otro lado, permite un abordaje de la complejidad de las construcciones de los campos de poder provinciales que, si bien comparten ciertos atributos específicos de la democracia con otros regímenes subnacionales argentinos -como las reglas de juego y los procedimientos electorales-, se diferencian de ellos por las limitaciones en otros de sus atributos vinculados con

2 En el Congreso del año 2009 organizado por la IPSA titulado "Problems of Democratization at the Sub-national Level" hubo una sesión sobre el tema. En abril del año siguiente Buenos Aires fue sede de la conferencia internacional “Democratización subnacional: América Latina, Estados Unidos, Rusia e India en perspectiva comparada" organizada por la Universidad Torcuato Di Tella con la colaboración de la Escuela de Política y Gobierno de la UNSAM y Mellon-LASA.

3 Por ejemplo, el Journal of Democracy en español del Instituto de Ciencia Política de la Pontificia Universidad Católica de Chile dedicó su volumen de 3 de julio de 2011 al "Autoritarismo competitivo". 
las libertades civiles y políticas. La estrategia de los subtipos disminuidos (Collier y Levitsky, 1998) ofrece una doble ventaja para este trabajo. Por un lado permite identificar en qué dimensión de la democracia se diferencia el caso analizado de otros regímenes subnacionales. Por otro lado supone que la relación entre democracia y autoritarismo, en lugar de ser planteada en términos dicotómicos o excluyentes, puede ser trabajada como dos polos de un continuum. Esta perspectiva nos permitió atender a los complejos vínculos entre Estado y régimen político observables en nuestro referente empírico.

La democracia, además de un tipo de régimen político ${ }^{4}$ y las garantías a los derechos civiles fundamentales, supone un tipo de Estado y una determinada relación entre este y la sociedad civil que la hace posible (O'Donnell, 2004; Oszlak, 2007; Iazzetta, 2007). Este punto ya fue advertido por el informe del PNUD La democracia en América Latina cuando señaló que "para producir el paso de la democracia electoral a la democracia de ciudadanía es central considerar la cuestión del poder del Estado y su capacidad para democratizar" (2004: 75). En el contexto de una estructura federal como la del Estado argentino, una problematización de la democraticidad en los niveles subnacionales constituye un aspecto pendiente en el debate político y en la agenda de investigación académica ${ }^{5}$. En general, los estudios que vincularon el Estado a la cuestión democrática lo hicieron desde el punto de vista de su reforma, su rol en la economía, el tipo de políticas sociales, los mecanismos de rendición de cuentas de los gobiernos. El Estado, además de ser un actor económico y social, es (o debe ser) el sustento de los derechos reconocidos y garantizados por la democracia (Iazzetta, 2007). Sin embargo, ha recibido escasa atención una dimensión medular del Estado: su poder de policía. Teniendo en cuenta que "el poder democrático se construye fundamentalmente en la estatalidad" (PNUD, 2004: 76), entendemos relevante la incorporación al debate sobre la democratización, los usos de la capacidad coactiva del Estado para comprender el tipo de vínculo con la sociedad civil al que estos dan lugar, y su relación con los problemas para construir una estatalidad democrática.

\section{EL PAPEL DEL ESTADO EN LA DEMOCRATIZACIÓN}

El régimen democrático necesita de un Estado cuyo sistema legal y sus burocracias sostengan y protejan los derechos y libertades que le son inherentes. Pese a que es uno de los actores fundamentales en las posibilidades de institucionalización de la democracia, el Estado ha sido el gran ausente del debate académico (O’Donnell, 1993). Esta ausencia podría relacionarse a la confianza en que el cambio de régimen traería aparejado la

4 La bibliografía relativa a los casos provinciales abordaron la realización de elecciones competitivas, limpias e institucionalizadas (Cheresky y Blanquer, 2004); los sistemas de partidos, leyes electorales y la competencia partidaria (Calvo y Escolar, 2005; Leiras, 2007); la división de poderes y el sistema de controles y contrapesos para el control de la legalidad de las acciones del gobierno y rendición de cuentas (Peruzzotti y Smulovitz, 2002; Abal Medina, 2009).

5 La tipología de zonas azules, verdes y marrones construida por O'Donnell constituye un antecedente importante para pensar el alcance desigual de su sistema legal a nivel territorial y funcional. 
transformación del Estado (Iazzetta, 2007). Los desafíos que en las últimas décadas deben enfrentar los países latinoamericanos demostraron que ni la democracia ni un Estado democrático se construyen por sí mismos. ${ }^{6}$ Uno de los temas de la agenda para el debate de las reformas democráticas en América Latina propuesto desde el informe del PNUD es la promoción de una nueva estatalidad como condición de ampliación de la democracia. ¿En qué sentido el Estado puede ampliar la democracia?

$\mathrm{Al}$ respecto se ha señalado que, además de asegurar los derechos políticos, el Estado puede fortalecer la democracia al asegurar y extender de manera homogénea los derechos sociales y civiles entre sus ciudadanos. Este trabajo estará centrado en las limitaciones que desde determinadas burocracias estatales se impone a ciertas libertades y derechos civiles fundamentales para el juego democrático. ${ }^{7}$

La relación entre el Estado y la cuestión democrática en general ha sido tematizada a partir de la eficacia de sus burocracias para cumplir con sus funciones, la efectividad de su sistema legal, la orientación de sus decisiones hacia el bien público y no hacia intereses particularistas (O'Donnell, 1993). La ausencia estatal en determinados sectores sociales y territorios locales y provinciales, ya sea en su dimensión burocrática y/o legal, o su captura por parte de poderes privatizados, darían lugar a una menor institucionalización de la democracia.

"Las regiones periféricas al centro nacional (que por lo general sufren más las crisis económicas y cuentan con burocracias más débiles que el centro) crean (o refuerzan) sistemas de poder local que tienden a alcanzar grados extremos de dominación personalista y violenta (patrimonial y hasta sultanista, en la terminología weberiana), entregados a toda suerte de prácticas arbitrarias. En muchas de las democracias que están surgiendo, la efectividad de un orden nacional encarnado en la ley y en la autoridad del estado se desvanece no bien nos alejamos de los centros nacionales y urbanos" (O'Donnell, 2002: 242).

Otras perspectivas sostienen que es necesario introducir reformas que permitan compatibilizar la tendencia a la centralización del poder que tiene el Estado y la tendencia a la descentralización de la democracia. En ese sentido se ha señalado la necesidad de promover un ejercicio desconcentrado del poder, una relación transparente del Ejecutivo con los otros poderes y órganos de control; la producción y acceso a información pública; el control sobre los recursos fiscales; la distinción público/privado (Iazzetta, 2010).

La capacidad del Estado para extender de manera homogénea los derechos civiles y políticos entre sus ciudadanos no se reduce a la eficacia de sus burocracias y/o la efectividad de su sistema legal, o el ejercicio desconcentrado de su poder. Este trabajo, planteado sobre la premisa de que tanto el Estado como la democracia son construcciones históricas y

6 La pobreza y la desigualdad social, las crisis económicas, la violencia institucional, la inseguridad que se experimentan en nuestra región han sido factores que han actuado en desmedro de los derechos sociales y civiles de sus ciudadanos y ciudadanas y disparadores de crisis institucionales.

$7 \quad$ No desconocemos que el nivel de desarrollo económico genera condiciones para la estabilidad democrática y que en ese sentido las políticas oficiales en materia económica impactan en los derechos sociales. 
contingentes, con trayectorias específicas, se centrará en una dimensión estatal central para la construcción de una relación democrática con la ciudadanía: su poder de policía.

\section{1. El poder de policía}

Poder de policía es una noción foucaultiana empleada por el lenguaje de las ciencias sociales para señalar la expansión del poder administrativo coactivo del Estado sobre el campo social con el fin de preservar lo que los sectores que ejercen la dominación definen como buen orden. Designa un conjunto de prerrogativas para limitar libertades públicas y derechos individuales (inherentes a un régimen democrático) que el sistema legal reserva al Estado con el objeto de dotarlo de herramientas para preservar un orden particular definido como orden público. ${ }^{8} \mathrm{Si}$ bien el poder de policía refiere a una atribución estatal más amplia, las prerrogativas mediante las cuales el Estado puede producir y reproducir orden social se materializan en los códigos contravencionales y las leyes orgánicas de las policías (Tiscornia, 2004). Nos centraremos en las segundas, ya que las policías ejercen, en el plano interno, el monopolio estatal de la violencia física legítima. En tanto las burocracias policiales son constructos sociales, no son impermeables a los intereses que dirimen en el campo político. No solo porque sus funciones y facultades son la expresión material de determinados programas de acción política (Oszlak, 2006), sino también por los usos que un gobierno puede hacer de dicho monopolio.

\section{2. Las policías provinciales en la estructura federal del Estado argentino}

La distribución orgánica y de competencia de los organismos de seguridad responde a la estructura federal del Estado argentino. De acuerdo con el art. 21 de la Constitución Nacional argentina los estados provinciales conservan todo poder no delegado al Gobierno Federal. Cada estado provincial determina sus instituciones de gobierno así como la estructura y normativa por la que se regirán cada uno de los tres poderes. Cada ejecutivo provincial constituye su fuerza policial a los fines de la seguridad y la investigación judicial. De modo que la policía depende, por su ministerio de gobierno, del poder ejecutivo y sus autoridades son elegidas por el gobernador. Esta ubicación institucional produce una notable dependencia de ministerios políticos, dando lugar a una policía funcional a los regímenes políticos de turno (Tiscornia y Oliveira, 1997):

"La policía es una profesión altamente sensible a las orientaciones políticas y, por lo tanto, depende poderosamente de la impronta de las políticas de Estado, ya sea nacional o provincial. La política de Estado es la variable que explica la orientación profesional de la policía y los usos o abusos que de su fuerza haga" (Frederic y Saín, 2008: 237-238).

8 En América Latina la defensa del orden público fue una de las justificaciones para el terrorismo de Estado. Supuso el disciplinamiento social mediante la eliminación física de aquellos actores sociales y políticos caracterizados como delincuentes subversivos. Por ello, el orden público ha sido más un resultado de la represión abierta que del consenso social (Oliveira y Tiscornia, 1992). 


\section{3. La politización de las fuerzas policiales}

Las burocracias policiales son una expresión material y brazo ejecutor de las distintas políticas de seguridad de un Estado nacional y/o provincial. En ese orden, la mayoría de las policías provinciales argentinas siguen conservando la estructura orgánicafuncional que adquirieron bajo las nociones de defensa y seguridad difundidas por la Doctrina de la Seguridad Nacional (DSN) entre las dictaduras instaladas en la región..$^{9}$ Las reformas implementadas por los gobiernos militares introdujeron criterios castrenses en la formación y adiestramiento de los agentes, la organización y funciones de la institución policial (Tiscornia y Oliveira, 1997; Dammert y Bailey, 2005; Frederic, 2008; Saín, 2008; PNUD, 2008). Subordinaron las policías provinciales a los objetivos militares de defensa del orden interno del "delincuente subversivo", que incluyó además de los movimientos guerrilleros a opositores o disidentes políticos y sociales (CELS, 1997). ${ }^{10}$ Esto produjo una "intensificación de prácticas policiales destinadas al espionaje, la invasión de la vida privada de los ciudadanos, el ejercicio de la coerción por motivos políticos y la creación de divisiones especiales para estos fines" (Tiscornia y Oliveira, 1997: 62). En ese marco se fundó dentro de las estructuras policiales provinciales el DIP / D2. En términos de poder de policía el DIP surgió como un organismo para el control político e ideológico sobre la sociedad civil y, en algunas provincias, la represión ilegal. ${ }^{11}$

Durante la transición democrática, el problema de los usos de la violencia estatal estuvo centrado fundamentalmente en la institución militar. A pesar de que participaron en la represión en el marco de sus facultades formales, la mayoría de los gobiernos provinciales no llevaron adelante reformas de sus policías. ${ }^{12}$ La permanencia de burocracias diseñadas por gobiernos autoritarios para el control político de los ciudadanos abre interrogantes sobre sus usos en la política democrática y plantea nuevos desafíos al debate sobre el vínculo entre Estado y democracia. El problema no se agota en la eficacia de la policía para cumplir sus funciones, como veremos en la siguiente sección, las prácticas de disciplinamiento político se encuadran dentro de las facultades conferidas por su ley orgánica y el reglamento interno del DIP.

$9 \quad$ La reforma de la policía bonaerense de 1997 actuó como punta de lanza para posteriores reformas introducidas en otras policías provinciales como las de Santa Fe, Mendoza, San Luis y Neuquén (PNUD 2008).

10 De acuerdo con Palmieri (1997), un antecedente de militarización y subordinación de las policías provinciales a las Fuerzas Armadas es el plan CONINTES de marzo de 1960. Con el reestablecimiento de la democracia en 1983 se dictaron nuevas leyes de Defensa Nacional (Ley $N^{\circ} 23.554$ ) y Seguridad Interior (Ley $N^{\circ} 24.059$ ) que produjeron una diferenciación entre ambos conceptos que fueron unificados por la DSN.

11 El informe Nunca Más elaborado por la CONADEP identificó como centros clandestinos de detención los D-2 de las policías de Córdoba, Mendoza, Misiones, San Juan, Jujuy y Santiago del Estero. En la actualidad está siendo investigada la participación del D-2 en actividades represivas durante la dictadura en el marco de los juicios contra los represores que se están desarrollando en las provincias de Mendoza, Córdoba, San Luis, La Pampa, Tucumán y Santiago del Estero.

12 Ver la séptima nota al pie. 


\section{LAS COMPETENCIAS DEL DIP EN LA ESTRUCTURA DE LA POLICÍA SANTIAGUEÑA}

La Policía de la Provincia fue creada en 1952, pero sus orígenes pueden remontarse a 1832 cuando el gobernador Ibarra fundó el Departamento de Policía. Su estructura burocrática se complejizó hacia 1971 con la creación de unidades regionales, direcciones generales y departamentos, entre ellos el $\mathrm{DIP}^{13}$, en el marco general de un proceso de militarización de las fuerzas represivas del Estado Nacional emprendida por el gobierno de la autodenominada Revolución Argentina (1966-1973). Pese a su origen autoritario, el DIP fue ratificado en 1974 por decreto del gobernador constitucional Carlos Juárez tras la suscripción del "Acta de compromiso de la seguridad nacional" de fines de 1973. Esta creaba el Consejo de Seguridad Nacional que fijaba nuevos mecanismos de coordinación entre las fuerzas de seguridad nacional y las policías provinciales para la intervención inmediata en caso de actos definidos como delictivos o atentatorios contra el orden público (Franco, 2009). La militarización de las fuerzas policiales, que supuso una homogeneización en sus leyes orgánicas, permitió su articulación al esquema represivo articulado por la dictadura militar de 1976. Con la sanción en 1979 de la Ley Orgánica $\mathrm{N}^{\mathrm{O}} 4793^{14}$ terminó de adquirir la estructura orgánica que la institución exhibe en la actualidad.

En su art. 15 del cap. IV establece como su función "procurar el mantenimiento del orden público, la represión de la delincuencia subversiva, la preservación de la seguridad pública y la represión de los delitos y faltas". En ese marco, es competencia del DIP:

“Dirigir la reunión de información, procesarla, evaluarla y difundirla en la medida correspondiente, programando las acciones a adoptarse en lo que a su especialidad respecta, y realizar tareas de contrainteligencia y la confección de los anexos y/o apartados correspondientes a su jefatura de los planes y órdenes del Jefe de Policía" ${ }^{15}$

Para la función de reunión de información cuenta con un organismo de ejecución, la Brigada de Investigaciones, que "actuará como organismo secreto de comando especializado y tecnificado, a fin de prevenir y reprimir el delito organizado". Para la función de reunión y organización de la información el D-2 contaba con 1) Sala de Situación, 2) Sala Explotación de Prensa, 3) Sala de Operaciones Especiales, 4) Sección de Archivos.

Pudimos identificar al menos tres tipos de informes en el archivo: 1) legajos personales que reunían: a) documentación y recortes periodísticos provistos por la Sala de Explotación de

13 De acuerdo con nuestra entrevista a un referente de la Asociación de Familiares de Desaparecidos y Ex-Presos Políticos de Santiago del Estero, el DIP tiene su antecedente en la creación de una policía especial en la década del cincuenta. En nuestra investigación pudimos identificar la creación en 1950 de 1) la Dirección Provincial de Defensa Nacional, 2) la División de Investigaciones y 3) la Inspección General de Jefaturas Políticas. Estos organismos cobran su sentido en el marco de las doctrinas de defensa y seguridad nacional que fueron delineando el montaje, dentro de la estructura de los Estados provinciales, de dispositivos policiales de vigilancia política.

14 La última Intervención Federal sancionó en noviembre de 2004 la Ley Nº 6689 que derogaba la ley de 1979. A la fecha no entró en vigencia.

15 Artículo N 175 del Reglamento de la Ley Orgánica Nº 4793 de la Policía de Santiago del Estero. 
Prensa, b) Informes ambientales sobre "las condiciones morales y el concepto que goza" la persona a base de la averiguación encubierta de la conducta, comportamiento, relaciones y hábitos sociales, c) Informes de calle resultante de la infiltración, seguimientos, escuchas telefónicas; 2) panorama ambiental diario constituido por los Informes Diarios elevados por los órganos de informaciones de las unidades regionales y comisarías. Estos registran la actividad producida en el "factor político", el "factor gremial", el "factor social" y en el "factor varios" como resultado de la infiltración y/o de seguimientos; 3) carpetas departamentales: que compilaban recortes periodísticos provistos por la Sala de Explotación de Prensa con publicaciones relativas al "factor político", el "factor gremial", el "factor social" producidas en cada departamento.

Para las tareas de inteligencia para producir información el D-2 contaba con una "cadena de informaciones" integrada por las "unidades regionales, comisarias y subcomisarias [que] deberán contar con una dependencia afín con las actividades que realiza el DIP" y asignar "personal policial que manifiesta una actitud especial para tareas informativas". ${ }^{16}$ Los organismos de la cadena de información intervinientes en la producción de información debían:

PUNTO 3. Llevar actualizado el panorama en relación a delitos comunes, actividades subversivas, asuntos políticos, gremiales, estudiantiles, migratorios, turísticos, etc., que tengan repercusión en la jurisdicción y por ende en el ámbito provincial [...]

PUNTO 4. Estos informes que son volcados en panoramas diarios deben ser profundamente analizados de inmediato e informar, y no limitarse a poner "sin novedad" en todos los rubros, recordando el estricto cumplimiento que ello debe ocurrir a diario y en término [...]

PUNTO 10. Recordar que el DIP (D-2) desarrolla actividades las 24 horas del día, de manera tal, que cualquier información llega en forma inmediata al conocimiento de la superioridad" (el resaltado con cursiva es nuestro). ${ }^{17}$

Dejando a un lado el delito común cuya prevención justificaría la existencia de las tareas de inteligencia ${ }^{18}$, estas tienen como objetivo una lista amplia de instituciones respecto de las cuales recabar datos como la nómina de autoridades, integrantes de sus comisiones directivas, con sus direcciones y números de documento. ${ }^{19}$ Esto revela la permanencia de una concepción de la seguridad tributaria de procesos políticos autoritarios donde la militancia política y social constituía una amenaza para el orden instaurado por las dictaduras.

La recolección de información sobre aspectos que no constituyen materia estrictamente policial suele desarrollarse dentro de un amplio marco de discrecionalidad. Los agentes

16 Documento interno del D-2 "Directivas para las Unidades Regionales, Comisarias y Subcomisarías".

17 Extraído de "Principales puntos que deben tener en cuenta los señores Jefes de Unidades Regionales, Comisarías y Subcomisarías en "Directivas para las Unidades Regionales, Comisarías y Subcomisarías".

18 La ley orgánica encuadra como delitos comunes a la trata de blancas, drogas y estupefacientes, contrabando y otras infracciones aduaneras.

19 Incluye autoridades y organismos de diferentes áreas del sector público, organizaciones de la sociedad civil, organizaciones religiosas, gremiales y profesionales, medios de comunicación, entre otras. 
disponen de un amplio margen de iniciativa y decisión en relación con aspectos que no están regulados, por lo tanto, suponen un elemento significativo de juicio personal en el desempeño cotidiano de sus funciones (Rico, 1983 citado en Saín, 2008: 105). En rigor, existe un conflicto entre el reglamento del D-2 sancionado por un gobierno de facto y las garantías contenidas en los capítulos 1 y 2 de la Constitución Nacional en las que se basa la Ley de Inteligencia Nacional 25.520 de 2001. La ambigüedad resultante de este conflicto atraviesa la práctica laboral de los agentes del DIP. El suboficial Ismael Pérez se desempeñaba como agente en el periodo estudiado y ejercía funciones en una de las secciones del organismo desde 1984. Explica que "no hay una reglamentación clara [...] el espionaje, si vos te vas a regir por la ley, no está permitido. Nosotros podemos actuar, digamos, en la vida privada de las personas o de las instituciones únicamente con orden exclusiva de un juez. Pero qué es lo que pasa... para que suceda eso el hecho tiene que estar ya explotado, tiene que haber dejado de ser latente". A la ambigüedad normativa, añade la falta de entrenamiento específico para las tareas de inteligencia: "cuando ingresé me dijeron: 'vos vas a trabajar con este' y yo seguía los pasos de ese [...] no había una instrucción fehaciente, no había preparación, era improvisar [...] encima no se podía venir sin nada".

En suma, las atribuciones formales del DIP han configurado una herramienta institucional a disposición del poder político, cuya continuidad no ha sido problematizada por los estudios sobre la democratización.

"Las instituciones policiales de nuestro país, lejos de constituirse como policías civiles y ciudadanas, fueron conformándose como guardianes del orden político y del disciplinamiento social y como policías militarizadas y estatalistas, más sensibles a las orientaciones e intereses de los gobiernos de turno y al control social disciplinante" (Saín, 2008:131).

Esta imbricación entre política y policía reflejada en las funciones políticas del DIP expresa, más que los acuerdos particularistas entre actores, que las burocracias son ámbitos permeables a las luchas de poder desplegadas en el campo político. La policial no es una excepción y este aspecto es importante para comprender algunas de sus prácticas institucionales.

\section{1. Los usos políticos del DIP en el juarismo (1995-2004)}

Los usos políticos del DIP pueden comprenderse a partir de los vínculos informales entre el PJ juarista y la policía sostenidos en la particular dinámica partidaria desplegada por el partido en relación con la institución, y en la creación de la Dirección General de Seguridad (DGS) en julio de 1995. En nuestra investigación encontramos que la dinámica partidaria descrita por los dirigentes como "trabajo político" constituye un saber práctico que se pone en juego en el campo político local. Designa conjuntos diferenciados de tareas de acuerdo con la posición partidaria y el género realizadas bajo un sistema de recompensas y castigos por el empleo público. Esto permitió a los dirigentes controlar designaciones, ascensos y retiros en cargos de la administración pública provincial, incluida la institución policial. El ingreso a la fuerza, muchas veces 
como una alternativa laboral a la desocupación, estuvo marcadamente condicionado por la presentación de avales políticos obtenidos en general como recompensa por la participación dentro de las redes partidarias. ${ }^{20} \mathrm{La}$ consecuente "politización de la policía" tuvo importantes consecuencias son significadas por algunos actores policiales como la desprofesionalización del personal policial y una alta cuota de discrecionalidad en la práctica policial, como quedó expuesto en los numerosos casos de violencia institucional denunciadas durante esta etapa. ${ }^{21}$ El Informe de Situación de los Derechos Humanos $(2003)^{22}$ señalaba que, de las 225 denuncias recibidas entre 1999 y 2003 por la Secretaría Diocesana para los Derechos Humanos, ${ }^{23}$ el $36 \%$ involucraba a la policía y $25 \%$ al PJ. De los casos denunciados, $27 \%$ correspondía a apremios ilegales, torturas, violencia policial y penitenciaria, $19 \%$ a abuso de autoridad e incumplimiento de deberes de funcionarios públicos, $17 \%$ a discriminación, $14 \%$ a impunidad, inseguridad jurídica y personal, inacción policial y judicial, $11 \%$ a asesinatos y desapariciones, $9 \%$ a persecuciones políticas, gremiales, policial, amenazas, y $2 \%$ a privación ilegítima de la libertad. Para ese mismo año, el Ministerio de Justicia, Seguridad y Derechos Humanos de la Nación publicó un informe donde, entre otros aspectos, denunciaba que "la institución policial aparece como un eficaz instrumento de dominación política. El importante número de casos de apremios ilegales, tortura y gatillo fácil protagonizado por efectivos policiales, como las tareas de inteligencia interna que dicha fuerza realiza, constituyen una de las cuestiones más lesivas al pleno desarrollo del Estado de derecho" (Informe Santiago, 2003: 40).

La politización de la policía a menudo ha sido interpretada como una manifestación de un "pacto de reciprocidad" entre autoridades gubernamentales y policiales consistente en el encubrimiento político y protección a jefes y cuadros policiales corruptos o vinculados con actividades delictivas, a cambio de "prestación de servicios políticos informales" de la policía como el espionaje y tareas de inteligencia o el hostigamiento y el ejercicio de presión sobre opositores y adversarios (Saín, 2008). Si bien la reciprocidad constituye un aspecto de la politización de la fuerza, los testimonios de los agentes policiales

“Existen numerosos casos de personal que ingresó a la fuerza sin cumplir todos los requisitos básicos. Además el acceso a los ascensos tanto para los suboficiales como para los oficiales está muy mediado por padrinazgos y lealtades" (Informe Santiago, 2003: 11).

21 "En el accionar policial se utiliza la metodología denominada del "apriete", que consiste en perseguir, golpear y a veces matar a aquellos que disienten del poder establecido. Los apremios ilegales, torturas y tormentos, como la utilización de bolsas de plástico para asfixiar a los detenidos, el quemarlos con agua caliente, colgarlos de las esposas, dejarlos desnudos expuestos a las bajas temperaturas, la picana, han sido denunciados con frecuencia a esta Secretaría y son prácticas policiales comunes para obligar a los detenidos a reconocer delitos" (Informe de la Secretaría Diocesana para los Derechos Humanos, 2003: 3).

22 Preparado por la Secretaría Diocesana para los Derechos Humanos del Obispado para una delegación de la Comisión Interamericana de Derechos Humanos.

23 En 1997 el Obispado de Santiago del Estero creó la Secretaría Diocesana para los Derechos Humanos para recibir denuncias relativas al abuso de poder y brindar asesoramiento jurídico y psicológico a los denunciantes. “La lucha emprendida por esta Secretaría se orienta a combatir las violaciones de los derechos fundamentales, que sistemáticamente van consolidando la cultura del miedo, del sometimiento y la dependencia en nuestra provincia, lo que impide el progreso y desarrollo de la comunidad [...] Por ello entre otros esta lucha está dirigida en contra del Poder Judicial y de la Policía de la Provincia, que con el poder que detentan, se constituyen en los principales operadores de la cultura del miedo, afectando a la dignidad de todos los santiagueños" (Informe Santiago, 2003: 18). 
entrevistados sugieren una relación de subordinación de los mandos y cuadros policiales intermedios a los dirigentes de los cuales dependía la continuidad en sus cargos.

A través de la DGS, un órgano político creado para relevar información requerida para tareas de gobierno, el Ejecutivo provincial pudo disponer de modo directo de los servicios del DIP que, desde un punto de vista formal, solo responde a requerimientos del Jefe de la Fuerza. Estuvo conformada por una Subsecretaría de Informaciones Policiales y una Subsecretaría de Seguridad en cuya dirección fueron designados dos represores: el Crio. (r) Antonio Musa Azar ${ }^{24}$ y el Mayor (r) Jorge D'amico, respectivamente. En el caso del primero, su carrera policial estuvo vinculada con el juarismo ${ }^{25}$ y tuvo injerencia sobre las designaciones, ascensos y retiros dentro de la fuerza pese a su retiro. ${ }^{26}$

La práctica policial forjada al interior del organismo es caracterizada por los policías entrevistados como un "modelo de trabajo" que comprendía tareas como "detectar cualquier tipo de conflicto", "desarticular cualquier situación contraria al régimen", según explica el comisario Juan Sánchez, quien se desempeñaba como sargento en el periodo estudiado. Pérez a su vez confirma que "había un tipo o un grupo de personas que evaluaban las diferentes situaciones que se daban en el ámbito de la provincia, en todos los ámbitos sociales, político, religioso, cultural, estudiantil". La evaluación era ejecutada por agentes de la Sala de Situación a base de la información revelada por la Sala de Explotación de Prensa, Operaciones Especiales y los panoramas ambientales diarios. Para los entrevistados la legitimidad de las tareas de espionaje político en un contexto democrático está fundamentada en la frecuencia con que esta práctica sería desempeñada por la mayoría de las policías provinciales: "el que cree que esas prácticas están perdidas está equivocado. Hoy por hoy, cualquiera y eso no es tampoco una cosa que suceda solo en la policía de Santiago del Estero, esa es una cuestión absolutamente normal, lógica y obligatoria en todas las policías", expresa el suboficial Pérez.

¿Qué particularidad tuvo el trabajo del DIP durante el juarismo? El espionaje político tuvo una doble orientación. Por un lado ambos policías coinciden en que se ejercía sobre referentes de la oposición política y social al juarismo. El comisario Sánchez revela que "si te tenían ubicado como que pertenecías a un determinado signo político, como que sos radical o que este es socialista, te marcaban". El testimonio coincide con lo señalado por el agente del DIP: "si protestabas te consideraban como un rebelde, como que querías desestabilizar al gobierno y te marcaban".

24 Musa Azar fue denunciado en el informe Nunca Más de la CONADEP, procesado y detenido por secuestro y desaparición de dos ciudadanos santiagueños por la Justicia provincial en 1984. A fines de 2003 fue imputado y detenido en el marco de la megacausa 9002 que investiga 45 detenciones ilegales y 14 desapariciones en el periodo 1973-1976 y 40 casos de detenciones y 17 desapariciones durante la dictadura. En 2010 fue condenado por la desaparición de Cecilio Kamenetzky el 9/08/1976.

25 El gobernador Juárez lo envió a la Escuela de Guerra del Ejército de Buenos Aires en 1973 para luego ascenderlo a Jefe del DIP en enero de 1975, designarlo Jefe de la Superintendencia de Seguridad y promoverlo al rango de Comisario. Durante la dictadura fue ratificado en su cargo y ascendido a Comisario General. Tras ser beneficiado por la Ley de Obediencia Debida retornó a la función pública el 19 de julio de 1995 como Subsecretario de Informaciones.

26 Informe Santiago, Secretaría Nacional de Derechos Humanos, 2003: 3. 
Por otro lado, "el tema era tener la información de dirigentes, de políticos, de cualquier persona que le interesaba al gobierno", "saber qué tipo de actividad estaba desarrollando, a qué signo político pertenecía, en qué cosas turbias o no andaban", reconoce el suboficial Pérez. Es decir, el espionaje también se ejercía al interior del PJ juarista. Los usos de la información permitían determinar si un dirigente "estaba o continuaba activamente trabajando en política para el oficialismo o no, si se ha pasado de bando, si cometían como ellos llamaban algún acto de traición que era ir en contra del pensamiento de ellos", señala el comisario Sánchez. En ese sentido Celia Fernández, una encumbrada dirigente del PJ juarista que llegó a diputada provincial en el periodo estudiado, relata que "a medida que ibas obteniendo cargos más importantes, estabas más controlado". Esto es consistente con lo señalado por el agente del DIP acerca de que "los diputados, los ministros, tenían temor a la Secretaría de Seguridad y al D-2 de Informaciones [...] porque sabían todos los movimientos".

En nuestro trabajo de campo encontramos que, debido a que la delación fue un recurso estratégico en la competencia por posiciones de poder dentro del partido, los actores políticos solían colaborar con el DIP. "Nos llegaba la información por el temor que tenían y por querer acomodarse (...) así nosotros no necesitábamos tener un aparato, es más, no nos costaba mucho el tema", revela el agente Pérez. Pudimos identificar al menos dos modalidades de colaboración: a) los informantes rentados financiados por la Subsecretaría de Informaciones que desempeñaban funciones como empleados en distintas áreas de la administración pública, ${ }^{27}$ b) los informantes informales que podían aportar datos de modo intermitente, en general bajo la modalidad del chisme, el rumor, la delación. Los colaboradores podían ser desde altos funcionarios de distintos estamentos del Estado (como jueces, ministros, diputados); empleados de diferentes categorías de la administración pública; dirigentes, referentes y militantes de las redes partidarias hasta dirigentes gremiales afines con el juarismo. La existencia de esta trama informal de colaboraciones es consistente con el contraste entre la cantidad de agentes que desempeñaban funciones en el organismo, apenas 30, con los cerca de 40 mil legajos de espionaje que fueron secuestrados del Archivo del DIP en los allanamientos de fines del año $2003 .^{28}$ Aunque el contenido de los informes podía ser manipulado y carecer de veracidad, esto no afectaba su eficiencia como estrategia de control disciplinante.

Un informe "negativo" podía poner en marcha al menos cuatro mecanismos de disciplinamiento político contra los opositores o disidentes: a) acoso laboral y cesantías, b) incriminación en hechos policiales, c) judicialización, d) amedrentamiento y agresión

“Tanto la Subsecretaría como el D-2 se apoyan en una red de informantes a los que la Subsecretaría paga un sueldo y que abarca todos los ámbitos de la administración pública y de la sociedad (...) sus sueldos según fuentes cercanas a este organismo oscilan entre 500, 1000, 1500 y 2000 pesos de acuerdo con la jerarquía y de la información que se pueda aportar". "Informe reservado. Una investigación sobre los servicios de inteligencia de la provincia". Suplemento El Liberal Investiga, 2000.

28 El primer allanamiento en el archivo del D-2 fue realizado el 6 de marzo tras el recurso de habeas data presentado por dos particulares. Al día siguiente se produjo un segundo allanamiento ordenado por la Justicia Federal en el marco de la causa por espionaje político. El segundo procedimiento fue monitoreado por organizaciones de derechos humanos y expresos políticos y la Oficina Antiimpunidad. 
física. Los informes remiten a la relación entre inteligencia y violencia. Durante la década del 70 si el DIP aplicaba la categoría "subversivo" sobre una persona esto implicaba su secuestro, tortura, asesinato o la desaparición en manos de las fuerzas de seguridad. ${ }^{29}$ Incluso en el interregno democrático entre 1973 y 1976 los informes tuvieron una traducción violenta. ${ }^{30}$ En la postdictadura, si bien el DIP no fue objeto de reformas democráticas, su función pasó de la represión al disciplinamiento político, del control de la delincuencia subversiva al control político.

Por último, el caso analizado muestra que la democratización de un estado requiere, como señaló el informe del PNUD, de la acción deliberada de las sociedades y sus gobiernos. La conservación y usos políticos por parte de gobiernos democráticos de prerrogativas estatales sancionadas por gobiernos autoritarios para restringir derechos civiles y políticos plantea obstáculos para la institucionalización de la democracia.

\section{CONSIDERACIONES FINALES}

La incorporación del poder de policía como una de las dimensiones que hacen a la democraticidad de un Estado nos permitió iluminar la persistencia de una burocracia policial orientada al control y disciplinamiento político de la sociedad civil y abrir interrogantes sobre sus usos en la política postdictadura. El recorrido realizado hasta aquí nos brinda herramientas para reflexionar sobre las implicancias que tiene el poder de policía que conservan algunos estados provinciales sobre la democratización.

La contradictoria coexistencia en el seno estatal entre la ley que organiza las incumbencias policiales, en particular las de su órgano de inteligencia, tributaria de una concepción autoritaria del orden y las garantías propias de un Estado de derecho, plantea un vínculo ambivalente del Estado con la sociedad por el que las libertades públicas de los ciudadanos se ve restringido por el control político. El caso analizado no se trata de una zona marrón donde habría una muy baja o nula penetración de la legalidad estatal, los controles del DIP expresan la presencia del Estado tanto en su dimensión funcional como burocrática. Es decir, la legalidad estatal está presente pero reconoce estratos, con temporalidades y funciones discordantes, de los que surgen prácticas institucionales contradictorias con un Estado de derecho. Las prácticas de control político del DIP, más

29 Recientemente concluyó el juicio a Musa Azar y a integrantes del grupo de tareas del D-2, Ramiro López Veloso y Miguel Tomás Garbi, por el homicidio, tormentos, privación ilegítima de la libertad de Cecilio Kamenetzky. Durante el proceso, su legajo fue un elemento de prueba de que el seguimiento determinó su secuestro: “98-76. El causante fue detenido por personal de este Departamento, ya que se tuvo conocimiento de que es integrante de una célula extremista de actuación en esta provincia" (El Liberal, 10 de octubre de 2010).

30 "La provincia no tuvo ni paramilitares como la Triple A, ni parapoliciales; los cuatro desaparecidos fueron signados como peligrosos gracias a los informes de Musa Azar, pero Musa Azar y los otros funcionarios no eran de la policía, eran empleados públicos de la provincia". Antenor Ferreyra (APDH) en referencia a las desapariciones de Emilio Ibarra el 13/03/76; Emilio “Chongo" Abdala (concejal del MID) 29/11/75; Daniel López Saracco 7/02/76; Luis Alejandro Lescano 13/03/76, "Final del régimen por genocidio y lesa humanidad", página 12, 22 de febrero de 2004. 
que acuerdos particularistas, expresan una función burocrática diseñada en un periodo histórico autoritario.

Un segundo desafío nace del conflicto entre la legalidad formal y la carencia de legitimidad democrática de una ley promulgada por un gobierno de facto que inscribe al trabajo policial dentro de una zona gris que repercute sensiblemente en la vigencia de las libertades públicas. La falta de legitimidad que envuelve a las funciones del DIP cobra mayor relevancia por su incompatibilidad con las garantías constitucionales que limitan al poder de policía instituido por un Estado autoritario. Estas tensiones se trasladan a la práctica laboral de los agentes del DIP, quienes cumplen funcionesmediante procedimientos que lindan la clandestinidad. El espionaje político a partir de seguimientos, escuchas telefónicas, infiltraciones es un ejemplo de ello.

La permanencia de las facultades formales del DIP como una de las herramientas institucionales de las que disponen los gobiernos para la vigilancia de lo que consideran orden público, abre interrogantes sobre sus posibles usos y la influencia soterrada en la articulación de procesos que discurren en el plano de la política institucional.

Por último, si bien podría decirse que las prácticas de uno de los organismos que forma parte del aparato burocrático no definen a la totalidad del Estado, también es cierto que la policía representa una dimensión medular de su poder. En ese sentido, la permanencia de organismos como el DIP no puede ser soslayada en el análisis de la democratización, ya que sus prácticas, además de ser disonantes con un Estado de derecho, ponen en entredicho la democraticidad del sistema político. Sin embargo, la política comparada y particularmente los estudios sobre el autoritarismo subnacional han desatendido la participación de otros actores que aunque estrictamente no forman parte de las instituciones del régimen político, inciden en la democratización de las relaciones entre Estado y sociedad. En nuestro recorrido observamos que un actor no político, como la burocracia policial, y un actor informal del sistema político, como las redes de militantes de un partido, pueden articular prácticas violentas y de control político que, aunque las afectan sensiblemente, no son tenidas en cuenta a la hora de problematizar los desafíos que enfrentan algunas de nuestras democracias. Es necesario incorporar al Estado en el debate académico y político sobre la democratización atendiendo que sus burocracias son espacios políticos complejos, con diferentes grados de democraticidad, donde los intercambios de actores estatales y no estatales entrelazan la política formal con las prácticas informales.

\section{REFERENCIAS}

Abal Medina, Juan Manuel. 2009. Participación y control ciudadanos: funcionamiento de los mecanismos institucionales electorales y societales. Buenos Aires: Prometeo.

Behrend, Jacqueline. 2011. "The Unevenness of Democracy at the Subnational Level. Provincial Closed Games in Argentina". Latin American Research Review 46 (1): 151-176.

Benton, Lucinda. 2007. Latín America's (Legal) Subnational Authoritarian Enclaves: The Case of México. Documento de Trabajo del CIDE Nº 196. México: CIDE. 
Calvo Ernesto y Escolar Marcelo. 2005. La nueva política de partidos en la Argentina: crisis política, realineamientos partidarios y reforma electoral. Buenos Aires: Prometeo.

CELS. 1997. Seminario sobre control democrático de los organismos de seguridad interior en la república Argentina. Buenos Aires: CELS.

Cheresky, Isidoro y Blanquer, Jean Michel (Comp). 2004. ¿Qué cambió en la política argentina? Elecciones, instituciones y ciudadanía en perspectiva comparada. Rosario: Homo Sapiens.

Dammert Lucía y Bailey John, 2005. Seguridad y reforma policial en las Américas: Experiencias y desafíos. México: Siglo XXI.

Diamond, Larry. 2002. "Thinking about Hybrid Regimes". Journal of Democracy 13 (2): 21-35.

Durazo Herrmann, Julián. 2010. "Neo-Patrimonialism and Subnational Authoritarianism in Mexico. The Case of Oaxaca". Journal of Politics in Latin America 2 (2): 85-112.

Franco, Marina. 2009. "La 'seguridad nacional' como política estatal en la Argentina de los años setenta". Antíteses 2 (4): 857-885.

Frederic, Sabina. 2008. Los usos de la fuerza pública. Debates sobre militares y policías en las ciencias sociales de la democracia. Buenos Aires: Universidad Nacional General Sarmiento.

Frederic Sabina y Saín Marcelo Fabián. 2008. “Profesionalización y reforma policial: concepciones sobre las prácticas de la policía de la provincia de Buenos Aires". En Estado, democracia y seguridad ciudadana. Aportes para el debate, Álvarez Alejandro, et al., Buenos Aires: PNUD Argentina.

Gervasoni, Carlos. 2005. "Poliarquía a nivel subnacional. Aspectos conceptuales y normativos en el contexto de democracias federales". Colección 16: 83-122. Buenos Aires: Pontificia Universidad Católica Argentina.

Gibson, Edward. 2006. "Autoritarismo subnacional: estrategias territoriales de control político en regímenes democráticos". Desafíos 14: 204-237.

Iazzetta, Osvaldo. 2007. Democracias en busca de Estado. Ensayos políticos sobre América Latina. Rosario: Homo Sapiens.

Iazzetta, Osvaldo. 2010. "Ciudadanía, Estado y democracia en la Argentina poscrisis 2001". Ponencia presentada en el Congreso de la Asociación de Estudios Latinoamericanos, Toronto, Canadá.

Leiras, Marcelo. 2007. Todos los caballos del rey: la integración de los partidos políticos y el gobierno democrático de la Argentina, 1995-2003. Buenos Aires: Prometeo.

Levitsky Steven y Collier David. 1998. “Democracia con adjetivos. Innovación conceptual en la investigación comparativa". La Politica: Revista de estudios sobre el Estado y la sociedad 4: 137-160

Levitsky Steven y Way Lucan. 2002. "The Rise of Competitive Authoritarianism". Journal of Democracy 13 (2): 51-65.

Levitsky Steven y Way Lucan. 2004. "Elecciones sin democracia. El surgimiento del autoritarismo competitivo". Estudios Políticos 24, enero-junio: 159-176.

Levitsky Steven y Way Lucan. 2011. "El aumento del autoritarismo competitivo". Journal of Democracy en español 3: 5-21.

O'Donnell, Guillermo. 1993. "Acerca del Estado, la democratización y algunos problemas conceptuales. Una perspectiva latinoamericana con referencias a países poscomunistas". Desarrollo Económico 33 (130): 163-184.

O'Donnell, Guillermo. 2002. "Acerca del Estado, la democratización y algunos problemas conceptuales. Una perspectiva latinoamericana con referencias a países poscomunistas". En Estado de derecho: concepto, fundamentos y democratización en América Latina, Joseph Raz, et al. (coord.), 235-264. México: Siglo XXI.

Oliveira, Alicia y Tiscornia. Sofía. 1992. La construcción social de imágenes de guerra. Buenos Aires: CELS.

Oszlak Oscar. 2006. "Burocracia estatal: política y políticas públicas". POSTData Revista de Reflexión y Análisis Político XI: 1-30.

Oszlak Oscar. 2007. "El Estado democrático en América Latina y el Caribe". Nueva Sociedad 210: 42-63.

Palmieri, Gustavo. 1997. "Normativa y estructura de los organismos de seguridad pública interior". Documento de trabajo del Seminario de control democrático de los organismos de seguridad interior en la República Argentina. Buenos Aires: CELS.

Peruzzotti, Enrique y Smulovitz, Catalina. 2002. Controlando la política. Ciudadanos y medios en las nuevas democracias latinoamericanas. Buenos Aires: Temas Grupo Editorial. 
PNUD. 2004. La democracia en América Latina. Hacia una democracia de ciudadanos y ciudadanas. Colombia.

PNUD. 2008. La educación policial: estudio de los sistemas educativos policiales de la Región NEA y de las fuerzas de seguridad y cuerpos policiales federales. Buenos Aires: Secretaría de Seguridad Interior y PNUD.

Saín, Marcelo. 2008. El leviatán azul. Política y policía en la Argentina. Buenos Aires: Siglo XXI.

Schedler, Andreas. 2002. "Elections Without Democracy: The Menu of Manipulation". Journal of Democracy 13 (2): $36-50$.

Schedler, Andreas. 2004. "Elecciones sin democracia. El menú de la manipulación electoral". Estudios Políticos 24: 137-156.

Schedler, Andreas. 2011. "La última línea de defensa del autoritarismo". Journal of Democracy en Español 3: 135-147.

Snyder, Richard. 1999. "After the State Withdraws: Neoliberalism and Subnational Authoritarian Regimes in México". En Subnational Politics and Democratization in México, Wayne, et. al (eds). San Diego: University of California.

Snyder, Richard. 2001. "Scaling Down: The Subnational Comparative Method". Studies in Comparative International Development 36: 93-110.

Souza, Celina. 2009. "Subnational Authoritarian Politics and Policy Choices in the Brazilian state of Bahia". World Congress of International Political Science Association, Santiago de Chile.

Tiscornia, Sofía y Oliveira, Alicia. 1997. "Estructuras y prácticas de las policías en Argentina. Las redes de la ilegalidad". Documento de trabajo del Seminario sobre Control democrático de los organismos de seguridad interior en la República Argentina. Buenos Aires: CELS.

Tiscornia, Sofía, 2004, "Entre el imperio del Estado de Policía y los límites del derecho. Seguridad Ciudadana y policía en Argentina". Nueva Sociedad 191: 78-89.

María Celeste Schnyder es investigadora en el Instituto de Estudios Sociales para el Desarrollo Social, Universidad Nacional de Santiago del Estero (UNSE, Argentina). Profesora adjunta en la Universidad Católica de Santiago del Estero. Es Licenciada en Sociología (UNS) y Doctora en Ciencia Política por la Universidad Nacional de Rosario, Argentina. E-mail: celesteschnyder@gmail.com 